\title{
C. S. Peirce on the dynamic object of a sign: From ontology to semiotics and back
}

\author{
Helmut Pape \\ Universität Bamberg \\ An der Universität 2, D-96047 Bamberg, Germany \\ e-mail: helmut_pape@web.de
}

\begin{abstract}
That reality, and in particular the (dynamic) objects of signs, are independent of our thoughts or other representations is a crucial thesis of Peirce's realism. On the other hand, his semiotics implies the claim that all reality and all real objects are real for us only because of the signs we use. Do these two claims contradict, even exclude, each other? I will argue that both Peirce's metaphysics and his semiotics provide a natural via media: a structural account of the openness of processes, featuring transitive relations, connects process ontology implicit in his evolutionary metaphysics and the relational, quasi-inferential features embodied in interpretational sequences of signs. It is shown that Peirce's notion of a sign, its normative role and his account of the directional force of objects implies a sort of logical causality that supports the unity of objects. In this way sign sequences are able to relate flexibly sign use with contextually specified independent objects. That is to say, relational properties of object-oriented chains of interpretations provide sign users with a flexible, fallibilistic instrument able to capture by contingent identity relations (teridentity) of the identity of objects in changing situations.
\end{abstract}

Keywords: dynamic object, interpretational sequences, object unity, process ontology, transitivity, Peirce's realism, contingent identity, inferential structures, teridentity, logical causality, collateral observation

\section{Introduction}

In order to understand Peirce's Dynamic Object (in what follows: DO), a top-down approach may prove helpful: We start with an ontological thesis and uncover its basis in semiotics. For Peirce develops an evolutionary metaphysics and an implicit process ontology by adapting semiotical and logical concepts, principles and insights. Of course, process is the ontological backbone of any dynamical account of objects. This ontological core of DOs has to be accounted for in logic in terms of inferential processes. This is what Peirce is driving at when he says: 
What is reality? Perhaps there isn't any such thing at all. As I have repeatedly insisted, it is but a retroduction, a working hypothesis which we try, our one desperate forlorn hope of knowing anything. Again it may be, and it would seem very bold to hope for anything, that the hypothesis of reality though it answers pretty well, does not perfectly correspond to what is. But if there is any reality, then, so far as there is any reality, what that reality consists in is this: that there is in the being of things something which corresponds to the process of reasoning, that the world lives, and moves, and HAS ITS BEING, in a logic of events. We all think of nature as syllogizing. (Peirce 1976: 343-344) ${ }^{1}$

What kind of dynamic character of objects is consistent with an ontology and metaphysics of processes? And what function might DOs have in inferential processes? To answer these questions we have to generalize the concept of an inferential process into a broad structural model. ${ }^{2}$ We adopt the assumption that all semiotic processes exhibit some sort of inferential structure. Actually, Peirce suggested a structural feature for all processes of an inferential character: the relational property of transitivity. Not only all syllogistic inferences but all sign processes that are actually completely realized will have to embody the property of transitivity. Transitivity is a property of relations and is essential for what in mathematics is called a relation of half-ordering. In medieval logic, describing the relation between terms is called the Nota Notae principle. It is called the principle of syllogism, if it represents the transitivity relation between propositions. The following is an example for this kind of inference:

"If Peter kisses Maria, then Eve is annoyed.

And when Eve is annoyed, she eats too much chocolate.

Therefore, Eve eats too much chocolate, if Peter kisses Maria."

In propositional logic the transitivity relation is a theorem that holds for three conditional propositions:

$$
[(\mathrm{P} \Rightarrow \mathrm{Q}) \&(\mathrm{Q} \Rightarrow \mathrm{R})] \Rightarrow(\mathrm{P} \Rightarrow \mathrm{R})
$$

Later on, I will prove the pivotal thesis of this paper that by those identity relations for which transitivity holds is we have sequential sign-processes capturing DOs. Still, first we will answer the more general question: why is the inferential structure of semiotic processes at all able to represent the dynamic identity of objects?

Our approach is faced with a number of questions: what are the success conditions for processes and what are those principles of inferences like that govern sign-processes

First published in Peirce 1976, vol. 4, but see also Peirce 1992: 161.

2 This project is somewhat similar to Robert Brandom's inferentialism in Making It Explicit (Brandom 1994), though only vaguely so because it does not share the restriction to language. 
with identical DOs? Also, it seems that we are running into an outright contradiction. For a realistic account of the DO in Peircean process semiotics gives rise to two conflicting claims: On the one hand realism requires that objects are dynamic and independent of our thoughts. On the other hand, these very same DOs are said to be captured by the internal inferential structure of semiotic processes for this is what governs their performance and is responsible for practical success. ${ }^{3}$

Of course, a contradiction can be avoided. We have just to make sure that there is a sufficiently rich, and open structure in sign-processes which makes room for all the corrections, changes and stimulations that an independently varying DO may confront us with. This relation between a sign process and an independent DO may nevertheless be a stable one, even if both types of entities are constantly changing. It is rather the stability of the chain of interpretation which is at issue, and it might be that neither the object nor the interpretations are stable. Only their "chained" interrelation is. Actually, this type of interrelation offers the only way Peirce's realism and fallibilism may be spelled out in terms of the logical and methodological demands for the practices of sign-processes.

First of all we have now to take a closer look at the details that make up Peirce's concept of an object. Let us start with the most controversial, metaphysical aspect of Peirce's concept of DO: this is the thesis that the DO of a sign acts analogously to a final cause or purpose. ${ }^{4}$ Or, to use a piece of terminology form physics and chaos theory, the DO resembles to some extent what is called an 'attractor'. For one, this implies that the DO is embodied into the logical structure of semiotical forms: its job is to structure sign-processes in such a way that some relational from properties analogous to those of purposes, goals, aims that govern human conduct become effective. The semiotical concept of the object is consistent with there being real, independent objects because this can be done in such a general way that their form allows objects to be dynamically parts of sign-processes, regardless of what changes in their properties might occur.

3 Here we can see why Peirce's semiotics is in some sense not far away from some version of radical constructivism. Please keep in mind that constructivism is just the modern counterpart of absolute idealism.

4 In Peirce's classification of the sciences objects are described as "final causes": "A natural classification, that is to say, a birth-al classification, is a classification whose governing idea coincides with the idea which determines the things classified to exist. An idea, so far as it has any relation to life, is a possible purpose. Therefore, the spirit of this work requires us here to regard a natural classification that conforms to the purpose or quasi-purpose, of the existence of the objects classified" (MS 1343, 00013). Later on he makes clear that this approach does not imply that there is a sort of Aristotelian teleological ontology in nature, but rather stresses the semiotic structure required: "Should there be no human purpose, there may, nevertheless, be an evolutionary agency that acts like a purpose, or there may [be] a principle similar to such agency except that it is related, not to a temporal, but to a logical sequence of results" (MS 1343, 00013). 


\section{Being determined / attracted by the object: Peirce's sign-definition and the role of the object}

All of Peirce's definitions of signs reserve a special, crucial role for the object of sign: the sign may determine an interpretant only, if there is an object to which the Interpretant and the sign both refer, and they do so because of the sign. The relation to the object via the sign determines the interpretant. This determination of an interpretant is what Peirce calls logical or semiotical causality. Therefore, the sign definition hinges on the object's logical causality. In one of the sign definitions this is brought out most clearly (MS 318, 1907):

[A] sign is anything, of whatsoever mode of being, which mediates between an object and an interpretant; since it is both determined by the object relatively to the interpretant, and determines the interpretant in reference to the object, in such wise as to cause the interpretant to be determined by the object through the mediation of this "sign". (MS 318, 44)

Here we can see that determination by the object is twofold: on the one hand, the sign is determined to have a specific interpretant, and, on the other hand, the object via the sign itself determines that the interpretant has the same object as the first sign it interprets. It is obvious that the causality involved in the object's determining function in the sign-relation cannot be physical causality. Rather, it is the object's logical causality which glues the material sign and its interpretant together into one unified sign relation. Therefore, the sign relation cannot be reduced, for example, to a mere two-place referential relation between two signs and one object. In fact, the sign-relation, is only complete as an integrated triadic relation. No set of two-place relations can have the same meaning and force (cf. CP 2.274).

This is the crucial question that the final causality interpretation has to answer: Why is the object's dynamical relation to the sign and via the sign to an interpretant to be explained analogously to a final cause, a purpose or aim, that influences human action in a teleological way? We start with some of Peirce's general remarks about the object. In one late MS he warns us:

that the common use of the word "object" to mean a thing, is altogether incorrect. The noun objectum came into use in the XIIIth century, as a term of psychology.

5 In the famous definition from the Lowell Lectures on logic from 1903 Peirce is quite explicit on this point. He relates the deterministic role of the object to the referential relation of the sign itself: "A sign [...] is a First which stands in such a genuine triadic relation to a Second, called its Object, as to be capable of determining a Third, called its Interpretant, to assume the same triadic relation to its object in which it stands itself to the same object". 
It means primarily that creation of the mind in its reaction with a more or less real something, which creation becomes that upon which cognition is directed; and secondarily, an object is that upon which an exertion acts; also that which a purpose seeks to bring about; also, that which is coupled with something else in a relation, and more especially is represented as so coupled; also, that to which any sign corresponds. (MS 693A, ${ }^{6} 33$ )

This fourfold characterization of the object is a philosophical gem. It explicitly brings together (1) the psychological; (2) the practical, directional and action-relative; (3) the relational positionality and (4) the semiotic and logical role of objects. All four features taken together describe of the dynamic status and force of an object, internally or externally considered. The symmetric counterpart of the directional force of the object is that an object may be "that which a purpose seeks to bring about". Another pair of symmetric counterparts is the following: an object existing in a relation to some other object, can, on the other hand, be a something which can be practically accessed by satisfying our purposes, aims, desires, wishes, goals etc. That is, some such object may be found, produced or known to be there. What this amounts to is: if the elements of directional relations and that of practical involvement in desires, etc., correspond to each other, the object of this double relational setting can be a dynamical one. Concerning objects, the analogy to final causality consists both in their role in the formal structure of sign processes and in the empirically embodied condition for the use and interpretation of signs.

\section{Logical causality and the Principle of Object Unity}

The next step is a detailed account of the internal structure that supports the analogy between DOs and final causes. Clearly, Peirce's concept of logical causality is based on a critical reconstruction of the traditional concept of final causality. So logical causality does not identify the finalistic relational structure active in signs processes with Aristotelian final causes or in general with human purposes consciously pursued. What is important is: this is not a revision of final causality but a new concept that applies to all cases where processes have an internal structure that approaches a final state. Therefore, Peirce uses 'finious' or 'finitistic' as better terms to denote this much wider range of phenomena. Explicit purposes, goals, aims etc., are then only the best known, everyday cases of finious causes, but the term 'attractor' refers to the same phenomenon.

6 Numbers prefixed by 'MS' refer to the microfilm edition of the manuscripts of C. S. Peirce as listed in Robins 1967. 
Of course, in the basic practical case there is no explicit, conscious purpose for signs to be determined by their objects. Still, the implicit logical causality unifying the sign relation, its finious structure, is embodied in our sign use in numerous types of practices. And these acquire an implicit normative role, for their success conditions require that interacting humans behave in coordinated ways. In fact, in contrast to the rationalistic approach, Peirce holds that explicit normativity presupposes that there already is a successful implicit normative practice in place. Just because DOs act analogously to final causes, logic becomes a normative discipline. This is already implicit in the sign-definition from 1907 in MS 318 quoted above. For in this quote the normative force of the object's logical causality is described as the link between signs and their interpretation. ${ }^{7}$

There are other consequences of this approach: if every sign and every thought is a representation of some object, our future interpretations and perceptions, thoughts and actions will tell us whether some actually used sign or thought was an adequate or true representation of the same object or not and whether it is identical with some dynamic, independent object. Of course, the position, order and properties of a DO might change. What our signs and thoughts try to achieve, however, is capturing the objects as far as we are able to identify them by whatever properties they may turn out to exhibit. This is Peirce's point when he says: "Identity' means a continuity, not necessarily in Place, nor in Date, but in what I may call aspect, i.e. a variety of presentation or representation" (MS 300).

How come that the logical causality in sign-processes actually captures the DO's identity successfully? Obviously, this can only be due to an internal structural feature of the form of sign-process that secures the identity of objects in whatever sequence of signs or representations that may come to pass. So we need a more complex form of structural relation that connects different representations and sign processes. In this way we transform the DO's identity into a requirement that governs sign processes. This identity can be captured neither by self-identity nor by Leibnizian indiscernability. That is, by the identity theorem that says that identical objects have to share all their properties. For it is clear that this would destroy the dynamics of change in the object.

The object's dynamic identity will have to be captured relative to a changing sequence of signs which we are able to understand to be determined by the same object. Dynamic identity is therefore "a variety of representation or presentation" for which Peirce introduces the terms "triadic identity" or "teridentity". Teridentity is a sort of

7 Signs are created and used by humans most of the time without the consciously pursued purpose of keeping up the object's dynamic identity in the sequence of signs. But in the event of their use this normative logical structure is always implicitly effective. Of course we can and do also explicitly structure with specific aims and purpose in mind. We do so some extent, for example in literature and scientific research. 
conjunctive identity which is the case, if at least two different representations of an object are captured in a third one, the identity statement. Peirce writes: "It is identity and identity, but this 'and' is a distinct concept, and is precisely that of teridentity" (CP 4.516). Teridentity gives us the identity of a DO only if we successfully connect at least two different signs, for example beliefs, about this object. Therefore, the schema of this type of representational identity is:

$$
(x)(y)(z) x=y \& y=z
$$

In the next step I will show that teridentity is indeed a formal property of signprocesses and that these processes may acquire the normative force outlined above. In his late semiotics Peirce realized that the identity of objects in signs has normative force. In 1908 Peirce even argues explicitly that in thinking we have to control the relation between signs and their objects and that for his reason logic and semiotics become normative sciences:

We think in signs; and indeed meditation takes the form of a dialogue in which one makes constant appeal to his self of a subsequent moment for ratification of his meaning in respect to his thought = signs really representing the objects they profess to represent. Logic therefore is almost a branch of ethics, being the theory of the control of signs in respect to their relation to their objects. (Peirce in a letter to P. E. B. Jourdain, 5.12. 1908, NEM vol. III, p. 886)

Logic, that is, semiotics, is a normative science when it describes how sign processes have a normative structure that keeps track of their objects. I will formulate a principle that generalizes this result. An object-related normative structure implies that in every sequence of signs a principle of object unity (PO) is at work. This principle may be stated in the following way:

(PO) If some sign $S 2$ acts as an interpretant of a sign $S 1$, then there is something a acting as its DO, if $S 1$ allows us to identify $a$ with something $b$, represented by an identity relation $a=b$. However, $a$ is a DO only if two conditions hold:

(1) $a=b$ is understood because S1 and S2 are connected by the sign relation; and

(2) $a$ and $b$ can be identified because of an independent second sign-relation of $S 2$ and $S 3$ for which the identity relation $b=c$ holds.

(PO) explains how teridentity for a DO depends on contingent identity relations in a sequence of consistently interpreted signs. That is to say, the sign-relation is connected to a possibly unlimited sequence of interpretations: all additional teridentity statements 
imply that they are parts of a sequence of signs about the same objects. And they imply the claim that the correct empirical conditions of the use of these signs are satisfied.

The (PO) for teridentity is a default principle of success. Of course, semiotic mistakes can always occur or we might fail to identify the independent object our signs claim to represent. Still, this is no argument against what happens in the normal case of all successfully represented DOs. To see this more clearly let us take a look at Peirce's example for a simple case of teridentity or triadic identity:

I see a man on Monday. On Tuesday I see a man, and I exclaim, "Why, that is the very man I saw on Monday." We may say, with sufficient accuracy, that I directly experienced the identity. On Wednesday I see a man and I say, "That is the same man I saw on Tuesday, and consequently is the same I saw on Monday." There is a recognition of triadic identity; but it is only brought about as a conclusion from two premisses, which is itself a triadic relation. If I see two men at once, I cannot by any such direct experience identify both of them with a man I saw before. I can only identify them if I regard them, not as the very same, but as two different manifestations of the same man. But the idea of manifestation is the idea of a sign. Now a sign is something, A, which denotes some fact or object, B, to some interpretant thought, C. (CP 1.346)

The point of this example is that success in identification of an object is what normally happens in our use of signs: the triadic sign-relation "A represents B for C", consists in the fact that a sign and its interpretant are automatically understood to be related to one another because they represent the same object. So (PO) describes in its first clause what it is for a sign and its interpretant to stand for an identical object: the sign in itself and its interpretant constitute a complete sign, if and only if they relate to the same object. The contingent identity is created only by such a sequence of signs which satisfies the teridentity condition.

This condition requires nothing spectacular but what happens normally when we use language or interpret signs successfully: we use a sequence of signs to reveal what object we want to convey something about. The important thing is, however: it is never just one single sign or interpretation but rather an open, never completed relation between different signs which allows us to grasp an identical DO. Rather, it is the object-oriented and identity-preserving form of a sequence of interpretations that might represent DOs more and more fully. ${ }^{8}$

8 But of course, although dynamically represented, no sign is a complete representation of its DO. This is a point Peirce argues for in 1902 when he says: "The sign is never the very object itself. It is, therefore, a sign of its object only in some aspect, in some respect. Thus, a sign is something which brings another sign into objective relation to that sign which it represents itself and brings it into that relation in some measure in the same respect or aspect in which it is itself a sign of the same sign. [...] Its own full aspect, the sign cannot evoke or endeavor to evoke" (MS 599, 36). 


\section{The immediate and the dynamical reality of the object}

We saw that we acquire semiotic access to DOs if there is a sequence of identity relations, possibly unlimited. At no point in time do we have to assume that the DO is completely understood and described. Still, the notion of the DO is consistent with the fact that sometimes we think of situational, fleeting objects that do not survive new experiences and interpretations. What is needed here is a piece of epistemological ontology: the concept of an object we grasp immediately, which may or may not lead us to an independent DO. Indeed, Peirce's late semiotics evolves around such a distinction between an immediate object and a DO and an immediate and a dynamic interpretant, completed by a final or logical interpretant.

But first let us take stock of what we know about the DO:

(1) The DO is independent of the sign and the sign is determined by the DO structurally.

(2) The DO is captured by an ordered sequence of interpretationally related signs in which the preservation of its identity acts like a final cause, connecting the signs with their interpretants.

(3) In particular, the DO is only understood because of an identity implicit in a sequence of actually used signs, where every second sign is an interpretation of every first sign representing it.

There is a tension between (1) claiming the independence of the sign's DO and (3) the dependence of our understanding of the DO from the sequence of signs. Let us discuss an example for which the existence of an object seems to be problematic. What is the object of a context-dependent assertion such as

(W) “This is a wonderful night”?

For the author and hearer of some token of (W) this use is connected to what they share in the very situation of this use of (W). So (W) has an object that according to the conditions 1-2 does not qualify as a dynamic one. In all such cases of contextdependent signs - the utterance of $(\mathrm{W})$ is a case in point - the situation the sign is used in and the sign are irreducibly connected: the token of this sign is part and parcel of the situation, in which we can grasp the object of the sign. For this reason the object cannot be understood apart from the situation of its use. All interpretations of signs like (W) will have to refer to the object and the situation it is used in, that is, be relative to an individual token. This, however, implies that

(4) all strictly context-dependent signs are token-reflexive: their interpretation has to acknowledge that they are self-referential because they refer to anything only relative to actually used tokens. 
(4) tells us that some signs, in particular indexicals, represent themselves and their object as parts of some situation of their use. However, such signs cannot pick out DOs independently of the signs they represent. Therefore, we need a distinction between types of objects, that is to say between different levels of access to objects. For surely, before we are able to grasp the contingent identity of an object in a sequence of signs, we already have some vague notion of what the object is like.

Interestingly, in 1907 Peirce (MS 318) describes the independence of the DO by requiring that this is a relation to an open community of observers, interpreters, that is, semiotic subjects:

(1) “The real is that which is independent of what any number of observers might think (or represent) about it.” (e.g. MS 318, 41)

However, what does independence mean in a situation in which an indexical sentence like (W) is used? Now, the first element of independence is that perceptual processes cannot be voluntarily controlled. The object of a sign automatically and subliminally grasped in perception is in this respect independent of the sign that will, later on, be its representation. In many cases, all observers will come up with the same perceptions.

Secondly, the independence requirement will be satisfied, if this perception of the object is carried out before, after or in complementation of the utterance of the sign. It complements the sign by supplying an external observational support. These are the reasons why Peirce talks of "collateral observation" - perceptual information that comes from the surrounding situation. Let us call this the "collaterality thesis" which consists of two closely related clauses. This is the first one:

(CT 1) The object of a sign is an idea that can only be gathered from collateral observation of circumstances that are independent of what is expressed or asserted by the sign (e.g. MS 318, p. 34). ${ }^{9}$

We observe the object independently in the actual situation in which the sign is uttered. But when the sign is only part of a semiotic context, that is to say, a text or visual display, we may perceive the object by independently observing the sign's relation to tokens of other signs. However, this means that a circular context-dependent of selfreferential tokens of signs is excluded: this phenomenon becomes part of the collateral observation of the object and the material sign. Although in this way an immediate object of a sign is grasped, this is consistent with there being also a DO that could be identified by collateral observations and interpretations.

9 Or, in Peirce's terminology: “[...] that idea which though essential to the functioning of a sign can only be attained by collateral observation is the idea of a strictly individual thing, or individual collection or series, or an individual event, or an individual ens rationis" (MS 318, 34). 
The first part of the collaterality thesis already implies that sharing a commonly accessible situation is fundamental for the way in which objects are identified. The author and the interpreter of the sign both use collateral observation to find out what object might be intended in the moment the sign is used. The object they have in mind is known to be shared because they both take it to be part of the present situation. Therefore, the utterer never has to say that what he or she is talking about is present here and now. In fact, if the utterer would try to describe what is present, this would be of no help. Peirce uses a nice example to show how the presence of shared collateral observation is indispensable for our understanding of language:

[I]f the utterer says "Fine day!" he does not dream of any possibility of the interpreter's thinking of any mere desire for a fine day that a Finn at the North Cape might have entertained on April, 19, 1776. He means, of course, to refer to the actual weather, than and there, where he and the interpreter have it near the surface of their common consciousness. (MS 318, 32-33)

The situational, immediate object of an indexical sentence like "Fine day" satisfies the independence requirement. This is the case because we arrive at an idea of an immediate object, as an "apprehension", by

collateral observation, aided by imagination and thought, will usually result in some idea, though this need not be particularly determinate; but may be indefinite in some regards and general in others. Such an apprehension, approaching, however distantly, that of the Object strictly so-called, ought to be, and usually is, termed the "immediate object" of the sign in the intention of the utterer. (MS $318,40-41)$

Clearly, the immediate object is only an "apprehension" of the DO, and cannot be real in the full sense of real, which would imply independence of the present thought or sign. The immediate object exists only "in the intention of an utterer" - and we may add, as an immediate interpretant in the understanding of the interpreter. In most cases of familiar objects, there will be a swift, unnoticed move from the immediate to the DO. For normally, we take it for granted that the immediate object is identical with "something real", that is to say, with a DO.

We saw already that (PO) is satisfied only, if there is a sequence of signs allowing for a contingent identity relation, that is, teridentity. But this complex identity following from signs interpreting one another one another and their objects is the case in all circumstances or contexts in which we perceive and act using signs.

The importance of the collaterality thesis in securing the independence of the DO is highlighted by its second clause, for it prevents that signs and objects are confounded. Peirce insists: 
(CT 2) The Object of a sign [...] is necessarily unexpressed in the sign taken by itself. (MS 318, 34)

Then the question is: how can we "know" an object, if the object is "unexpressed" by the sign "taken by itself"? In 1907 Peirce distinguishes and connects his concept of an immediate and dynamic of object by saying:

This [...] I term the Object of the sign; - the immediate object, if it be the idea which the sign is built upon, the real object, if it be that real thing or circumstance upon which that idea is founded, as on bed-rock. (MS 318, 33)

Although the immediate object has only an intentional status, this already means that the real object is the one to be grasped. It is in this sense that the DO represented by the transitive form feature acts as a final cause.

Normally, we form the idea of the immediate object of a sign in the following way: already before the sign is uttered we have a huge stock of observations, opinions, knowledge about the context or situation from which the object idea may be selected, but what is decisive in forming an immediate object is what we pick up from the observation in the actual situation of sign-use.

The conclusive way of picking out the present object is by collateral observation operating in the present situation of sign use. In the situation the sign is used in, we execute observations of what is perceivable right now with the goal of building up an idea of a stable, DO. Therefore, we always tend to conceive more of an object than what we actually perceive, designing an object that may exist independently the present situation of sign use. This is Peirce's point when he argues: "the DO does not mean something out of the mind. It means something forced upon the mind in perception, but including more than perception reveals" (PW, 197).

According to (CT 2), if the sign is taken by itself, its object will remain "necessarily unexpressed". Above we saw that the (PO) requires that we have to consider a sign in relation to other signs with the same object, if we want to know the identity or sameness of their DO. That is to say, although "a sign cannot express its Object, it may describe, or otherwise indicate, the kind of collateral observation by which that Object is to be found" (PW, 37).

We should keep in mind that describing the sort of observation needed to identify the object of a sign as presented in experience, is not expressing an individual object by a sign. By indicating the kind of action necessary to access an object, by identifying the universe of discourse, the realm things and signs, that is to say, the relevant kind of individual object, we do establish relations to other signs. For example, an observation of the interpreter guided by an indexical component of the sign may allow him to pick out the real object in the situation in which the sign, e.g. "What a fine day!" was used. 
If the sign is a sentence, it may have a subject term that expresses a logical quantity like "all”, "some", "any", etc. These logical expressions can be understood as describing the selection of instances of objects to which the predicate of the sentence is applicable and which are identifiable by collateral observation. That is to say, the sign contains a quantified expression, and this quantification is to be interpreted in what is nowadays called the game-theoretical sense. This is what Peirce is driving at when he points out:

Thus, a proposition whose subject is distributively universal ... such as "Any man will die", allows the interpreter, after collateral observation has disclosed what single universe is meant, to take any individual of that universe as the Object of the proposition, giving, in the above example, the equivalent "If you take any individual you please of the universe of existent things, and if that individual is a man, it will die". (MS 318, 37-38)

In this way we may now give (PO), the principle of object unity, a logical reading: to be a DO of a sequence of signs may be, for some authors and interpreters, the search path for an observable instance that satisfies a quantificational expression expressing a relation between co-interpretational and co-referential signs resulting in collaterally accessible observations of the DO intended.

It is time to look again at the thesis that the role of the DO is analogous to that of a final cause. One reason supporting this thesis was presented above: the identity of any object gives rise to a normative stance, turning logic into a normative science. The DO's identity can only be represented, if it acts like a purpose in a sequence of sign processes trying to represent it. That is to say, teridentity is a transitive relation and in sign processes representing an object it is performed in order to capture an aspect of the identity of a common object.

For Peirce the most comprehensive structural feature of sign processes is their growth in sequences of correlated interpretations. The question of the truth of a teridentity claim resulting from a sequence of signs is the question of whether the process of transformation of one sign into another actually represents the identity of the object. This is what Peirce expressed in 1906: "The highest kind of symbol is one which signifies a growth, or self-development of thought, and [...] accordingly, the central problem of logic is to say whether one given thought is truly, i.e. is adapted to be, a development of a given other or not" (CP 4.9). Any process that creates a dynamic identity, or teridentity, instantiates some sequence of signs that has a strict order: it is transitive and asymmetrical. A transitive sequential relation like " $\mathrm{X}$ is a sign for everything Y stands for", has, as the quote shows, a most basic task to perform. This task is fundamental for knowing anything: it is our only chance to know the identity of what we want to think or talk about - some sort of a dynamical object. ${ }^{10}$

10 This paper is based on an invited lecture "Dynamiken der Religiongeschichte zwischen Europa und Asien” presented at the Käte Hamburger Kolleg on 24 October 2013. 


\section{References}

Brandom, Robert B. 1994. Making It Explicit: Reasoning, Representing and Discursive Commitment. Cambridge: Harvard University Press.

Peirce, Charles S. 1931-1958. Collected Papers of Charles Sanders Peirce. Cambridge: Harvard University Press. [Hartshorne, Charles; Weiss, Paul; Burks, Arthur W. (eds.). In-text references are to $\mathrm{CP}$, followed by volume and paragraph numbers.]

- 1976. The New Elements of Mathematics by Charles S. Peirce. (Eisele, Carolyn, ed.) The Hague: Mouton. [In-text references are to NEM.]

- 1992. Reasoning and the Logic of Things: The Cambridge Conferences Lectures of 1898. (Ketner, Kenneth Laine, ed.) Cambridge: Harvard University Press.

Robins, Richard S. 1967. Annotated Catalogue of the Papers of Charles S. Peirce. Amherst: University of Massachusetts Press.

\section{Ч. С. Пирс о динамическом объекте знака: из онтологии в семиотику и обратно}

Одним из основных тезисов пирсовского реализма является утверждение, что действительность и в особенности динамические объекты знаков не зависят от наших мыслей и иных репрезентаций. С другой стороны, в его семиотике содержится утверждение, что вся действительность и все реальные объекты реальны для нас только из-за знаков, которыми мы пользуемся. Эти два тезиса противоречат друг другу или даже являются взаимоисключающими? Я утверждаю, что метафизика Пирса и его семиотика предлагают натуральную via media: структурный обзор открытости процессов, содержащих транзитивные отношения, соединяет скрытую в его эволюционной метафизике процессуальную онтологию с воплощенными в интерпретационных последовательностях знаков реляционными, квазиинференциальными чертами. В статье доказывается, что пирсовское понятие знака, его нормативная роль, понимание роли направленной силы объектов имплицируют логическую причинность, которая поддерживает единство объектов. Таким образом, реляционные свойства направленных на объект интерпретационных цепочек дают пользователю знаками гибкий, фаллибилистский инструмент, с помощью которого становится возможным уловить отношения идентичности (teridentity) объектов в изменяющихся ситуациях.

\section{C.S. Peirce märgi dünaamilisest objektist: ontoloogiast semiootikasse ja tagasi}

Et tegelikkus ning eriti märkide (dünaamilised) objektid ei sõltu meie mõtetest ega teistest representatsioonidest, on üks Peirce'i realismi põhiteese. Teisalt sisaldab tema semiootika väidet, et igasugune reaalsus ja kõik reaalsed objektid on meie jaoks reaalsed üksnes märkide tõttu, mida me kasutame. Kas need kaks väidet on teineteisele vasturääkivad või isegi teineteist välistavad? Väidan, et nii Peirce’i metafüüsika kui ka tema semiootika pakuvad välja loomuliku kesktee: struktuurne kirjeldus protsesside avatusest, millesse kuuluvad transitiivsed suhted, seob tema evolutsioonilises metafüüsikas peituva protsessiontoloogia ning tõlgenduslikes 
märgijadades kehastunud relatsioonilisi, kvaasiinferentsiaalseid jooni. Näidatakse, et Peirce'i märgi mõiste, selle normatiivne roll ning tema kirjeldus objektide direktsionaalsest jõust viitab sellisele loogilisele põhjuslikkusele, mis toetab objektide ühtsust. See tähendab, et objektile suunatud tõlgendusjadade relatsioonilised omadused annavad märgikasutajatele paindliku, fallibilistliku instrumendi, mille abil on võimalik tabada objektide identiteedisuhteid (teridentiteeti) muutuvates olukordades.

\title{
COMMENT
}

\author{
Francesco Bellucci ${ }^{11}$
}

One of the main theses of Helmut Pape's "C. S. Peirce on the dynamic object of a sign" is that the identity of a sign's dynamic object is captured by the internal inferential structure of the semiotic process. Since for Peirce the structure of semiotic processes is governed by (a generalization of) the transitive relation, it follows that the determination of the identity of a sign's dynamic object is itself governed by the transitive relation. From this some consequences follow concerning identity. Among other things, Pape argues that the conception of identity as Leibnizian indiscernibility is unable to capture the changes in the dynamic object (assuming a process ontology); only the transitive relation of teridentity can determine the dynamic identity of a sign's dynamic object.

I will add two brief notes to Pape's argument, one concerning the object of a sign and the claim that the object is independent of the sign, the other about teridentity.

1. Inference consists in deriving conclusions from premises:

Logic seems to be the science of the relations of symbols in general to their objects. A logical inference is true if its premises are true. In other words, that inference is logical which conforms to the general conditions of passing from premises which have a real object to a conclusion which has a real object. (W1, 309, 1865)

An argument is the expression of an inference. An argument is a sign, i.e., the sign that suchand-such premises represent such-and-such conclusions. An inference is valid when it never (or rarely) leads from true premises to false conclusions. The passage quoted in the article from Peirce's 1908 letter to Jourdain states exactly this: logic is the "theory of the control of signs in respect to their relation to their objects"; that is, the theory of the control that one is passing from a sign with an object to another sign with the same object, i.e., which is true when the former is true.

It seems that the term "object", in contexts such as Peirce's definition of logic as objective symbolistic in 1865 , has the dimensionality of a structured fact, a state of affair; for only states of affairs have a truth value, and when Peirce says that logic studies the relations of symbols

${ }^{11}$ Author's address: Department of Philosophy, Tallinn University of Technology, Ehitajate tee 5, 19086 Tallinn, Estonia; e-mail: bellucci.francesco@gmail.com. 
to their object he evidently and explicitly means the truth of symbols. But as pointed out by Hilpinen 1992, Peirce more often uses “object” for the things denoted by the proposition's subject(s). It is in this second sense that later, in 1904, he came to talk of a dynamic object of the sign, and it is in this sense that "object" is used in Pape's paper. But let us resist the temptation of equating the immediate object with the object in the sense of a structured fact. Rather, the classifications of signs suggest that Peirce's immediate/dynamic object distinction has something to do with quantification (as reported in my article in this volume).

Helmut Pape is much concerned with the apparently contradictory claims that (1) the object is independent of the sign, and that (2) our understanding of the object depends on the sequence of signs. Signs only function in contexts: "[S]ome signs, in particular indexicals, represent themselves and their object as parts of some situation of their use. However, such signs cannot pick out a DO independently of the signs it represents." So, it is argued, there is a contradiction between the independence of the object from the sign, and the fact that the identity of the object is determined by the sign and the context of its use.

The contradiction is dissolved as soon as we take (1) as signifying not that the object is independent of the sign tout court, but that the object is independent of how the sign represents it to be. The object is such-and-such independently of being represented as such-and-such in the sign: the cat is either black or not black independently of being represented as black in the sign "the cat is black". A sign is true when its object is as it (= the sign) professes or represents it to be (cf. the letter to Jourdain: "signs really representing the objects they profess to represent"). The dynamic object is as it is independently of what the sign says of it; but the dynamic object is not independent of the fact that the sign indicates it: the object is identified by the sign (through an immediate object), and in this obvious sense it does depend on the sign. But its characters do not depend on what the sign represents those characters to be.

In brief, the contradiction is avoided as soon as we recognize two parts in a Peircean sign: one is deputed to represent, i.e., to indicate the object (quantification over the universe of discourse), while the other is deputed to represent, i.e., to describe the object (predication). This, however, can only happen if signs are bipartite or bipolar entities, that is, only if the model and prototype of a Peircean sign is the proposition (see Stjernfelt 2014).

2. Pape justly remarks that the conception of teridentity is central in Peirce's mature philosophy of logic. In the passage quoted by from CP 1.346 (Lowell Lecture III, 1903) Peirce explains that while dyadic identity may be directly experienced ("I directly experienced the identity"), triadic identity is the fruit of inference ("a recognition of triadic identity; but it is only brought about as a conclusion from two premises"). Peirce also shows that teridentity is more primitive than identity, and thus that the latter can be dispensed with in a perfect system of logical representation (i.e., Existential Graphs, cf. MS 498, 490, 1906; MS 300, 1908; MS 670, 1911). But is teridentity a form of inference in the proper sense, as Peirce suggests in CP 1.346 and as Pape maintains?

The relation, or better, the graph of teridentity is introduced in the systems of graphs as an essential element of analysis:

if a graph expresses a concept analytically, its analysis must be logically correct, and the only logically correct analysis from elements all of which are expressed in the graph. This is plain, since all that we mean by a logically correct analysis is one 
in which the elements are so put together as precisely to express the concept to be analyzed. Thus, Fig. 1, is the only correct analysis of the idea of a ram that does not proceed further and analyze either the concept of a sheep or that of a male.

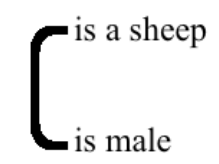

Figure 1

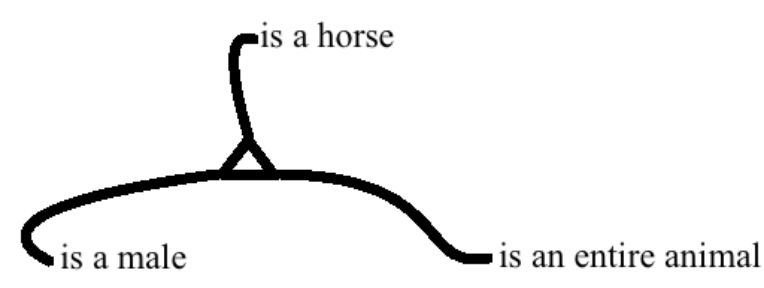

Figure 2

In like manner, Fig. 2 must be a correct analysis of the concept of a stallion. [...]In this Figure, the partial graph $\Delta$ means "- is identical at once with - and with a co-identical -”. The analysis of Fig. 2 must, for the reason given, be the sole correct analysis that is not pushed further. Consequently, the analysis represented in the Algebra of Dyadic Relations by the non-relative product (Horse $\cdot$ Male $\cdot$ Entire), where two black dots express each only simple identity, and not coidentity, or as I prefer to say, teridentity, must be wrong. This false analysis cannot be expressed in existential graphs at all. (MS 296, 1908)

In a normal system with only the sign of simple, dyadic identity (=), a rule or axiom (transitivity of identity, Euclid's first axiom that things equal to a third are equal to each other) is necessary to prove the identity of more than two things: if $a=b$ and $b=c$, then $a=c$. It is not possible in this system to represent the logically simultaneous identity of $a, b$, and $c$ without using more than one single sign. The same is true of Peirce's Beta graphs: with the simple, dyadic relation of identity represented by lines of identity it is not possible to represent the identity of three distinct things but in two distinct logical steps and by employing rules of transformation (insertion, branching, attachment of lines). The graph of teridentity, once introduced, dispenses with the reference to the axiom at all and directly represents identity as a multi-valency relation. In this sense, it as it were "embodies" the axiom. The graph of teridentity has also the effect, as Peirce notes already in 1882, of rendering the distinction between relative and non-relative operations superfluous (W 4, 396-397).

The same is true of the relation of conjunction or co-existence. The necessity of introducing the commutative and associative rules in the calculus is only due to the notation's inability to represent unordered and associative relations as such. In linear notation we introduce the rules $a \& b=b \& a$ and $a \&(b \& c)=(a \& b) \& c$, while in EGs - where conjunction is represented by unordered juxtaposition of two or more graphs on the sheet - these rules are unnecessary as they are already contained in the conventions of the notation. As Dipert (2006: 306) rightly remarked, "the symmetric, commutative 'spirit' of conjunction suggests that we should create a notation that capturesthis unordered aspect of the pure logical notion of conjunction, in order not to introduce artifacts of order in our notation and then have to take steps to remove them by introducing 'rules of inference' for the 'commutativity' of conjunction". Juxtaposition as it were "embodies" the rules of commutation and association. 
Conjunction is, like teridentity, a triadic relation. Peirce says that a copulative proposition " $P \& Q$ " "predicates the genuinely triadic relation of tri-coexistence, ' $P$ and $Q$ and $R$ coexist.' For to say that both $A$ and $B$ is true is to say that something exists which tri-coexists with true replicas of $A$ and $B$ " (EP 2, 281, 1903). The assertion of the conjunction of two propositions $a$ and $b$ is equivalent to the assertion that there is something (the universe of discourse) in which $a$ and $b$ coexist. Hence, the graph of coexistence is to be considered as a triad. Identity and coexistence are degenerate forms of the genuinely triadic predicates of teridentity and tri-coexistence. These predicates are impermeable to logical analysis, and for this reason Peirce calls them "continuous" (MS 611, 1908, CP 8.352). In fact Pape (1989: 277-279) was the first to describe correctly continuous predicates as elementary forms of logical combination. In EGs, continuous predicates are represented by continuous graphs (MS 293, 1907). A correct logical analysis is one in which no analysable element remains unanalysed; therefore, the only correct analysis is the one in which every logical predicate is a continuous predicate. For the purposes of logic there is no point in analysing further the graph in Figure 2 above. Of course it is always possible to push the analysis further and analyse 'male' as in Figure 3, so as to have Figure 4:

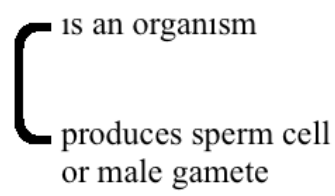

Figure 3

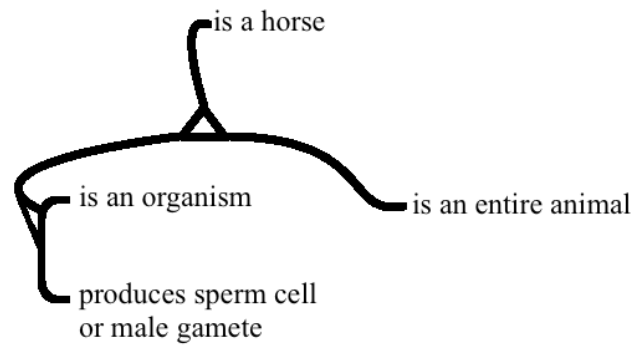

Figure 4

But logic is not interested in such semantic, material analyses. This is why Peirce adds the proviso that the analysis through the graph of teridentity is "the sole correct analysis that is not pushed further". What logic is concerned with is the analysis of second-intentional, not of first-intentional, relations; and in this respect the graph of teridentity analyses any alternative relation of simple, dyadic identity, as the graph of coexistence (Sheet of Assertion) analyses any alternative relation of simple, dyadic coexistence.

Teridentity and coexistence are in no obvious sense "inferences". They are logical relations that are at once transitive and continuous (MS 516, 33-39, 1903), and thus unanalysable. But they are at the same time "sclerotized" patterns of inference, relations whose logical structure embodies what in alternative, less analytic systems of logical representation would be expressed by an axiom or a rule of transformation. 


\section{References}

Dipert, Randall R. 2006. Peirce's deductive logic: Its development, influence, and philosophical significance. In: Misak, Cheryl (ed.), The Cambridge Companion to Peirce. Cambridge: Cambridge University Press, 287-324.

Pape, Helmut 1989. Erfahrung und Wirklichkeit als Zeichenprozeß. Frankfurt am Main: Suhrkamp.

Peirce, Charles Sanders 1931-1966. The Collected Papers of Charles S. Peirce. (8 vols., Hartshorne, Charles; Weiss, Peter; Burks, Arthur W., eds.) Cambridge: Harvard University Press. [Intext references are to $\mathrm{CP}$, followed by volume and paragraph numbers.]

- 1967. Manuscripts in the Houghton Library of Harvard University, as identified by Richard Robin, Annotated Catalogue of the Papers of Charles S. Peirce. Amherst: University of Massachusetts Press. [In-text references are to MS, followed by manuscript number and, when available, page number.]

- 1982-. Writings of Charles S. Peirce: A Chronological Edition (7 vols., Moore, Edward C.; Kloesel, Christian J. W. et al., eds.) Bloomington: Indiana University Press. [In-text references are to $\mathrm{W}$, followed by volume and page numbers].

Stjernfelt, Frederik 2014. Natural Propositions: The Actuality of Peirce's Doctrine of Dicisigns. Boston: Docent Press. 